\title{
Measuring the Turnaround in Business Performance due to WMS and MES Implementation in a Process Manufacturing Client
}

\author{
Sushant Siddharth Wanjari
}

\begin{abstract}
The Warehouse Management System (WMS) and the Manufacturing Execution Systems (MES) have proven to be of massive help in increasing the organization's productivity and its ability to execute key logistic functions with great efficiency and effectiveness. The process manufacturing industry has a unique setup and requires good collaboration between the different elements of the supply chain to operate at the highest efficiency. At the same time, the shop floor operators must have a good understanding of the new WMS/MES systems to derive maximum benefit from them. This paper dwells into the business improvements witnessed by an alcoholic beverage client after successfully implementing the WMS and MES solutions. The paper includes a literature review of the benefits and risks in WMS/MES implementation. Also, the literature is supported by a case study wherein the client's business and operational challenges are discussed, and the improvements resulting from the project implementation. The WMS and MES were found to have a positive impact on business performance and it was observed that a project of such scale needs diligent planning and effective implementation for maximum benefits.
\end{abstract}

Index Terms - Warehouse Management Systems, Manufacturing Execution Systems, ERP Implementation, Process Manufacturing.

\section{INTRODUCTION AND LITERATURE REVIEW}

The main goal of a warehouse is the efficient management of goods storage and transfer, while optimizing space use and accurately locating all stored items at any moment [1]. But [8] citing Richards states that "Inventory accuracy, space utilization, process management and picking optimization are the major challenges in modern warehouse management." A contributing factor is that customer requirements have evolved due to the variety of available products, and the resulting increased need for real-time data and accuracy, has proven that manual warehouse operation leads to low efficiency and is unable to adapt to the changing market [8]. Also, for food and beverage companies, the reduction of spoilage and the improvement of order shipment accuracy is essential for business, and this can be hindered by the use of manual or paper-based processes [4]. Thus, it is logical to take advantage of the rapid growth in technological advancements and incorporate innovative technology and software-oriented tools to solve the issues faced by these companies.

The Warehouse Management System is a software solution designed to improve the traceability of goods, the accuracy and visibility of inventory movements, the throughput via integration with other software solutions, the labor productivity, and space utilization, as well as reducing the need for paperwork [4]. Hence, wholesalers implement WMS with the objective of optimizing fulfillment strategies and enhancing performance, and a correct implementation can result in optimal inventory accuracy along with complete traceability of products [3]. Also, the dynamic reports produced by the WMS systems assist supervisors by alerting them to potential issues before they occur [3]. The vast real time information provided by the WMS can then be utilized to enhance decision making, for planning purposes, and general improvements in management.

The implementation of WMS systems in beverage companies has increased steadily in recent years, one of the major drivers is the increase in picking windows, due to the improvement of order reception and its contribution to an efficient workflow management [7]. [8] states that within the warehouse operations, the order picking process can reach $50-55 \%$ of the total operating expense. Hence, an improvement in picking efficiency can produce considerable savings for the company. [7] states that Brown-Forman's Ford increased its throughput by $20 \%$ after just two months of implementing a WMS system, and shipping errors were reduced from 3 to $0.3 \%$. Lastly, WMS systems provide a multitude of advantages for companies seeking to improve productivity and efficiency.

Furthermore, increased globalization, competition, ecommerce sales, and the wide availability of products has required the restructuring of manufacturing lines from the previous linear production line model [9]. Consequently, the manufacturing segments also require the use of technological tools to maintain relevancy in a changing market. Therefore, Manufacturing Executions Systems (MES) were established to manage shop floor activities from the order reception through to the finished product, and it centers on optimizing the production schedule and shop floor conditions [6]. The MES is used to monitor, control and optimize the manufacturing processes, improve connectivity, link enterprise and shop floor levels, support computerization, provide key information to decision makers, ensure transparency, increase predictive capacity, and improve adaptability [5]. These goals can be achieved by decreasing machine downtime, enhancing delivery times, augmenting production levels, and optimizing the workers schedules and the employed tools [9].

Published on October 23, 2020

Sushant Siddharth Wanjari.

(corresponding e-mail: swanjari@ gmail.com) 
The application of ERP, WMS, and MES provides clear advantages to companies, but the implementation can be challenging due to system complexities, the necessity of experienced IT employees, and the obligation of extensive organizational changes [1]. Another difficulty faced by WMS and MES are cybersecurity issues, since these systems utilize cloud services, they can be vulnerable to cyber-attacks and privacy breeches [5]. This can prove problematic for companies that do not possess an experienced IT department and can incur additional costs to ensure the security of the systems. Lastly, MES are short term planning systems that highly depend on manual employee tasks, such as rescheduling deliveries and analyzing the provided information before deciding [2]. This dependency creates opportunities for human errors and delays, and the future of these systems is the inclusion of automation to provide a solution for the human error.

\section{THE CASE STUDY}

\section{A. About the Client}

The client considered for the study is a major alcoholic beverage producer in Asia, founded approximately 100 years ago. It produces and markets a wide range of beer, ciders, spirits, wine and ready to drink beverages. The study considers the client's operations in Asia Pacific, where it has 9 main breweries which cater to the entire market. Over the years the client has grown inorganically through various mergers and acquisitions. As a result, there were many systems and practices in place which were not in perfect harmony with each other.

\section{B. Business Problem}

Each brewery of the client produces a range of products and makes contract manufacturing for global brands under licensing arrangements. Because of the inorganic growth, each brewery had their own operational process and from the managements perspective the business operations were running okay. But it did not possess enough data/information to make correct business decisions to minimize costs and improve productivity.

There was a significant challenge posed by the entry of large global players in the marketplace and the emergence of craft brewers. The large players were introducing established global brands, whereas craft brewers were introducing new and unique products in the market. Given the plethora of options to the consumer, the client was feeling the heat of competition and it showed in the downward trend of its market share over the last 5 years.

The client was not dealing effectively with its raw material suppliers, which stems from the fact that the systems were not efficient in material planning. The purchase orders were placed to suppliers via email or phone and by the time the delivery came to site a variation in production schedule would occur, leading to a sudden demand of several raw materials. This would jeopardize the production schedule, put stress on suppliers, and occupy the warehouse space with the materials not urgently required. Part of the problem was associated to poor planning and part of it was due to the manual reception of the inbound deliveries from the supplier. Each reception would take significant time to record in the system, print the label, and store in the final bin location in the warehouse.

There was an apparent problem with the way production was executed. The raw materials were received physically and booked into the legacy system, then the process order to make a beverage was released for execution. All the packaging raw materials (glass, crowns, beer, carton, pallet, etc.) necessary to execute the process order would be supplied by the warehouse to the production line. The material delivery process to the production line was completely manual, wherein the operator would have a printed list of the materials to be picked and delivered to the packaging line. At the end of the production run, the unused or leftover raw materials in the line were returned to the warehouse. At this time, the warehouse would do a stock take and reconcile the stock. But there were often delays in doing the stock take due to a busy work schedule, a smaller number of resources, and other operational reasons. Thus, the inventory accuracy was always a matter of concern to the management.

The packaging line in production was dependent on the timely delivery of raw materials to keep the line running at optimum speed. The line operators would communicate with the warehouse operator over radio walkie talkies to know the status of the delivery. The manual picking and delivery to the line often depended on the soft skills of the operators. While the production worked fine most of the times, there were instances of production downtime at critical points due to delayed material delivery to the line or insufficient availability of the raw materials. Also, the legacy systems used by the production and warehouse operators acted independently and there was no visibility to either group regarding the work schedule of the other side.

The client also faced product recall from market in the past due to mismatching product and packaging. This brings disrepute and poses regulatory risks from authorities.

\section{Business Solution}

Whilst the threat of competition is not new in the business, a sustained threat causes anxiety in senior management. The emergence of craft brewers and the entry of global players made the client's management look deeper into their business performance and evaluate the executable measures to keep themselves relevant in the market. They concluded that the business process and systems they were using were highly diversified and there weren't enough performance indicators in place to evaluate the cost of production versus the generated revenue. Thus, they decided to undertake a major transformation program to replace the old systems with the new-age ERP and MES systems covering Finance, Human Resource, Customer Service, Logistics, Sales, Purchasing, etc. While the client implemented the entire ERP suite of applications, this paper focuses on the impact caused by the WMS and MES systems only.

\section{METHODOLOGY}

The research methodology utilized in this study is the single case study with a quantitative approach. The key components of the WMS and MES implementation project were carefully analyzed for how they address the business problem. Post implementation, key indicators were analyzed 
to gauge the change in business performance. A survey of selected people, comprising of senior management to the shop floor employees, was conducted using a questionnaire to understand the change impact. In the subsequent sections, a brief overview of the different critical elements of the project are presented, and lastly the research findings are discussed.

The survey respondents comprised of:

- Material Planning team - Responsible for procurement of raw materials and stock transfers.

- Production Execution team -Team leads and members managing the production line.

- Warehouse Execution team -Team leads and members managing the warehouse receipts and issues.

- Senior Management - Senior leadership team at the site. This research considered the four hypotheses below:

- H1: Having large suppliers connected via ERP results in better integration and efficient supplier collaboration.

- H2: Having a reliable WMS improves internal supply chain performance.

- H3: When the WMS and MES are connected seamlessly, they bring out the optimum productivity.

- H4: New age WMS and MES solutions have a considerable advantage over the traditional legacy systems.

\section{CASE DESCRIPTION}

The client engaged with a reputed consulting firm for the implementation of the project. As a starting point, the client identified key businesspeople with sound knowledge of the business process. The consulting firm had a team of functional and technical experts to recommend the best system solution for each of the business requirements. Thus, a core project team was formed and together they developed a target operating model for the client. Two breweries, one large and one small, were selected for the template solution build and pilot implementation. The rationale behind the two-pilot site selection was that the solution built for the pilot sites would be easily extended to the remaining breweries of different sizes and complexity. The overall aim was to develop a robust yet simplified solution capable of improving efficiency and transparency by re-engineering the business processes. During the process, the project team was also developing a 'single way of working' across the client's manufacturing facilities. The solution was carefully designed considering scalability and the client's historical growth and future business expansion plans.

\section{A. WMS Solution Key elements}

The WMS solution was developed to address the problems associated with inventory accuracy, paper-based picking, and work allocation to operators.

\section{1) Supplier Integration}

One of the problems identified was the troublesome purchasing process, and to solve this issue a supplier integration software was implemented. The ARIBA software is a proven purchasing management tool with exceptional benefits to both buyer and seller. The client identified the key vendors who supply the bulk of packaging materials and are critical for the supply chain performance. The identified vendors were onboarded to Ariba and a unique account was created for each of them. This created a new experience to the client and suppliers because now all purchase orders and scheduling agreements had to be raised via Ariba. Anyone from the client side wanting to make a schedule change had to login to Ariba to see the open purchase orders, confirmed delivery schedule and all other relevant information, and then proceed to make an informed and sensible decision which would not disturb the production schedule and the imminent deliveries from the supplier. Also, the supplier must send an electronic Advanced Shipment Notification (ASN) for the planned deliveries. The ASN would present delivery schedule and pallets per incoming delivery, thus informing the warehouse of the expected delivery load and timings to allow for receipt planning. During the physical reception of deliveries, the warehouse operators could use the Radio Frequency guns to scan the ASN and SSCC barcodes on the pallet followed by unload and storage into the warehouse. The largest benefit of this was the end to end traceability of each pallet from the supplier to receipt in warehouse and issue to the process order. The Ariba portal helped in streamlining not just the ASN and delivery of goods, but also the invoicing and the payment settlement as well.

\section{2) Paperless Picking}

The warehouse operators underwent a considerable change in their traditional work procedures due to the arrival of Radio Frequency guns. The traditional paper-based picking was replaced by technology driven work allocation and scanning based picking. The WMS solution was built by analyzing the daily operator tasks and subsequently developing a system solution which efficiently streamlines the daily activities while minimizing idle time. The warehouse layout was designed by creating different zones and assigning the picking and put-away into that zone to a dedicated queue. The operators had to login to the RF gun and select the RF queue, which directed them to execute the picking or put-away tasks in the corresponding zone. In the picking process, the RF gun would require the operator to go to specific bin and scan the bin barcode to start picking. Then, the RF displays the information on the product, batch, and quantity to be picked, which the operator must pick up to confirm the pick execution. Thereafter, the RF provides details of the destination for that pallet, which can be either the production line or outbound staging area, depending on the pick request The operator then takes the pallet to the suggested destination and scans the location to confirm pick completion. Once the specific task is completed, the next task in the queue is displayed to the operator to repeat the steps and execute the next pick/put-away task. In doing this, the operators need not depend on anyone for any information and the RF task execution proved to be working very efficiently. Production supply fulfilment was designed so that all demands from production go to the WMS to create the pick task assigned to the appropriate RF queue. A team lead is assigned to monitor the warehouse workload during the entire shift and communicate with operators to select an appropriate queue and balance out the workload. To cater for a sudden demand from production, a dedicated 'priority' queue was created so that anytime production operators asked for expedited 
delivery of certain raw material, the team lead in that shift would identify the pending task for that material and change the queue assigned to that task to priority. He would then ask the available warehouse operator to select the priority queue and execute those tasks.

\section{3) Inventory Accuracy}

The information on raw material inventory in the legacy systems was not sufficiently accurate and the regular cycle counts resulted in massive variances. The new WMS solution was tightly integrated with the purchasing, production execution and sales departments. The picking or putaway requests were created in the WMS with reference to either a purchase order, production order, or sales order. The stock picked or put away in the WMS for any of the reference documents, updated the inventory figures in the WMS and sent the updated information to the sales, purchasing and production systems instantly. The WMS stock information detailed the number of pallets per materials and the exact location of those pallets in the warehouse, whereas the other inventory reports outside of the WMS reflected the net quantity per material. Thereby the overall inventory figures remained in-sync across the different reports and different users had real-time accurate information on the inventory in hand. Secondly, the instant updates of the inventory removed the need for warehouse operators to do a cycle count after every production order run. Thus, removing the redundancies in the process and allowing operators to focus on the active workload. As a result, only the bins with high stock movements were considered for regular counts.

\section{B. MES Solution Key elements}

The Manufacturing Execution System (MES) was designed considering the overall information needed by the production operator to ensure that packaging lines in production keep running smoothly. A typical packaging line setup is shown in the image below. It comprises of different work centers namely: Depalletiser, Filler, Labeller, Packer and Palletizer.

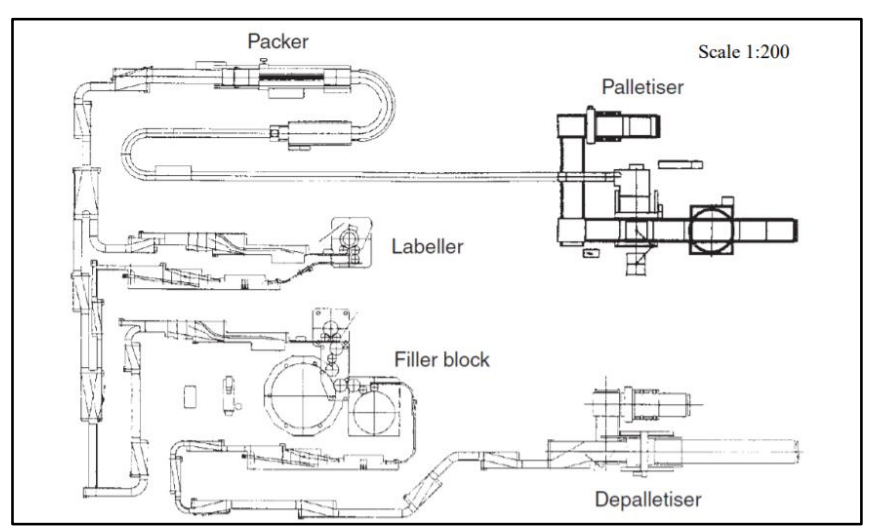

Fig. 1. Packaging line setup.

Depalletiser is the start of the packaging line where pallets of empty bottles or cans are fed or loaded. The bottles or cans are cleaned with nitrogen before moving to the Filler block, where they are filled with liquid beverage and sealed with crown. Labeller involves labelling each bottle, and at Packer the filled and labelled bottles are packed into cartons. Finally, at Palletizer, the packed cartons are assembled onto a pallet, shrink wrapped, and the SSCC label is applied onto it. Each work center receives a specific raw material delivered from the warehouse. The delivery from the warehouse occurs gradually while the line is running because there is limited floor space at the work centers in production. There is a production operator allocated to each of these work centers whose responsibility is to maintain the healthy running of packaging line at their respective work center.

\section{1) Operator Dashboard}

Each work center was provisioned with a desktop computer where the production operator can login and access a central dashboard. They can select the right work center from the dashboard and view the planned orders for the day per shift. Further, they can begin working on the active order, start a new order, or stop the running order. At any point of time, there can be only one active order. Lastly, the dashboard had multiple options for the operator such as:

- Material Issues - allows to check the net material requirement for the active order and track the pending consumption.

- Report Production - helps the operators on the palletiser work centre know the net quantity produced for the active order and make sure the pallets meet the standards.

- Manage Downtime - record downtime for any known/unknows reasons.

- Quality Dashboard - for filler operators to keep track of all the quality checks done on the active order and keep tracking.

\section{2) Scanning to Issue Materials}

The work centers were also provisioned with a scanner connected to the desktop computer. The raw material pallets delivered by the warehouse had an SSCC barcode on it. To issue materials to the active process order, the operator must first scan the barcode to validate the material being issued is part of the active order. Upon successful validation, the operator proceeds to physically unload the raw material pallet to the work center. This process guaranteed that incorrect materials were not issued to the active order and bigger downstream issues like product recall from the market are avoided at the root.

\section{3) Automatic Quality Notifications}

The filler is one of the most critical elements on the packaging line and it is subjected to frequent quality checks on the liquid to record parameters like alcohol percent, $\mathrm{pH}$, acidity, color, etc. The quality checks take place at fixed intervals and the dashboard was designed to give pop-up notifications when the quality inspection time has reached. This allowed for timely inspection recording. The operator also has an option to view all the inspections completed for the active order and check the results of each inspection.

\section{WMS MES Integration}

There was a genuine need for the production operators to know the schedule of material deliveries to the packaging line and for the warehouse operators to have visibility of the production schedule for the day and week. The project team developed innovative options on the operator dashboard which can read the WMS and present useful information to production operators on the expected material delivery at their work center. Also, the warehouse operators had a 
custom report at their disposal to view the production schedule.

\section{1) Pending Material Overview}

The operator dashboard provided an option for the production operators to see the current stock of raw materials at their work center and the pending warehouse deliveries to that work center. Thus, allowing the production operator to maintain the operations running smoothly, knowing they have enough stock at their disposal and there are planned deliveries coming once the current stock is issued. Also, the dashboard included an option to trigger the return to the warehouse at the end of the production run. Once the returns were initiated, an automatic task would be created in the WMS to pick up the unused or partly consumed pallet from production floor and move it to the warehouse. All these options were aimed at removing the manual communication between operators.

\section{2) Halt Delivery}

The production schedule was prone to changes due to many business reasons and it could happen at any time. Sometimes the production order was released, then a decision was made to stop the order due to change in customer demand or non-availability of resources. Also, on occasion the active order had to be stopped prematurely due to a breakdown or quality issues at the filler. All these changes had a negative impact on the in-progress warehouse tasks. Usually the warehouse gets a lead time to deliver materials to production, but the last-minute schedule changes caused the unwanted materials delivered to the line which had to be moved back to the warehouse. To counter this, another option was built on the operator dashboard to halt the delivery of pending materials. If an active order is to be closed prematurely or a new order is released for production and subsequently cancelled, the production operator can put a 'halt' against that order. This triggers a message to the WMS to cancel the pending deliveries for all raw materials associated to the halted order, thereby reducing the unwanted pallet movements between warehouse and production.

\section{3) Report on Production Schedule}

A custom report was built specifically for the warehouse operators to be able to see the production schedule. The report had an option to display the schedule for the user's selected date or range of dates. This report helped the warehouse ensure there is enough stock in-hand and planned deliveries for the required raw materials. They used the report to flag the material shortfall to the purchasing team, who would connect with the material supplier and request for expedited deliveries to keep up with the production schedule. It also gave the warehouse managers an opportunity to do resource planning and shift planning to ensure there are enough people available to execute the planned workload in the warehouse.

\section{ANALYSIS}

The data collected from the survey questions and primary data from the MES and WMS reporting was analyzed to find answers to the research hypotheses. This section details the evidences collected in the form of graphs and charts to interprets the results.

\section{A. H1: Having suppliers connected electronically results in better integration and efficient supplier collaboration. \\ 1) Inbound Receipts summary}

Inbound Receipts

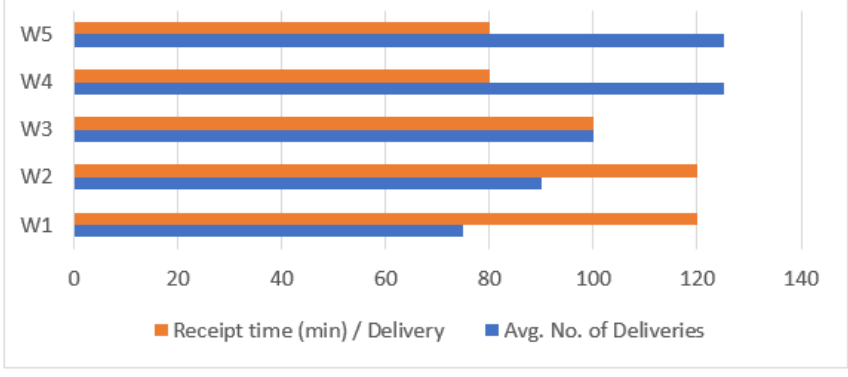

Fig. 2. Inbound receipts summary.

The graph above shows the average number of deliveries received and the average receipt time in minutes for each delivery. Figures are from week 1 to week 5 after going live with the implementation. It is seen that the number of deliveries received steadily increased from 75 in week 1 to 125 in week 5 , and the average receipt time per delivery was reduced from $120 \mathrm{~min}$ to $80 \mathrm{mins}$. On average each delivery consists of 20 pallets and this data considers that only one operator was responsible for the entire reception and storage.

2) ASN Accuracy

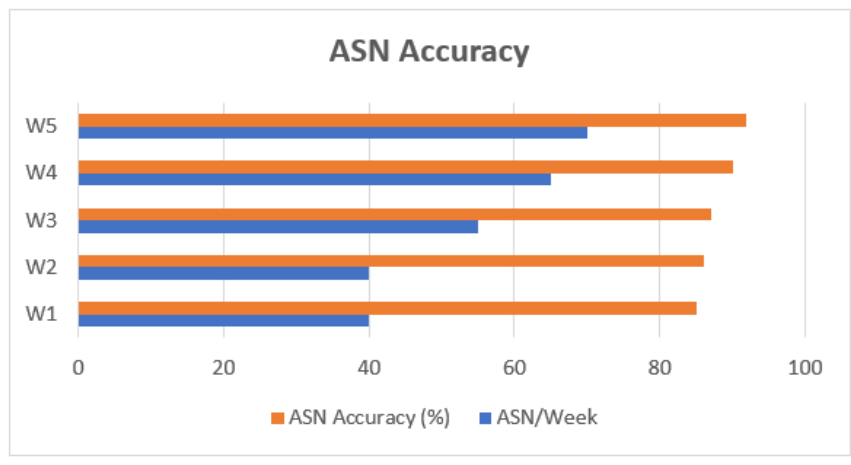

Fig. 3. ASN accuracy summary.

The Advanced Shipment Notification (ASN) is sent electronically by the supplier. The graph in Fig. 3 represents the total ASNs received versus the ASN accuracy from week 1 to week 5. ASN accuracy is measured in terms of the conformity of the electronic information to the physically received stock. It was observed that the supplier interface went into errors while processing the supplier messages due to master data issues. It was also observed that some suppliers had better compliance in comparison to other suppliers. The number of ASNs per week increased from 40 in week 1 to 75 in week 5, and the corresponding ASN accuracy increased steadily from $85 \%$ in week 1 to $92 \%$ in week 5 .

\section{3) Simplified GR Process}

Approximately 40 warehouse operators responded when asked about the simplification in the goods reception (GR) process in the new WMS solution. About $85 \%$ of respondents confirmed that the GR process was simplified, whereas $15 \%$ of users did not see an improvement. 


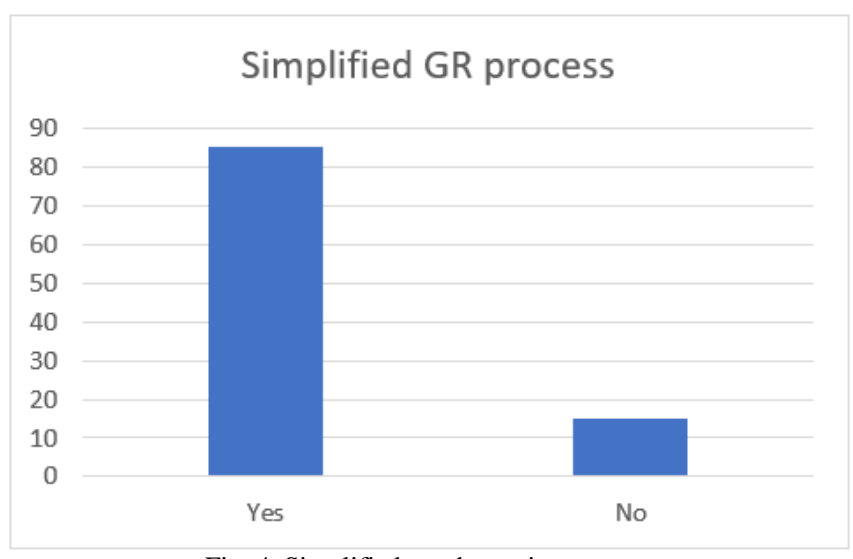

Fig. 4. Simplified goods receipt process.

\section{4) Supplier Scorecard}

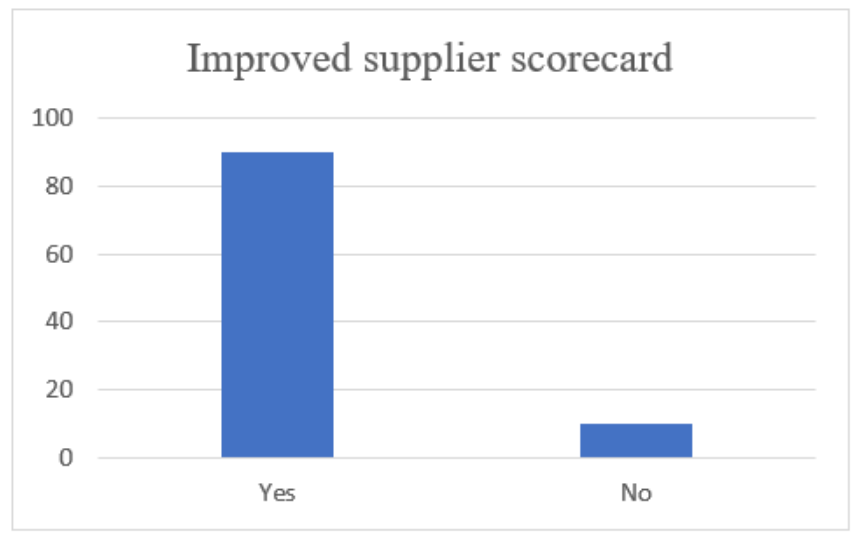

Fig. 5. Supplier scorecard.

Around 20 people members of the client's purchasing team across breweries responded when asked if the supplier was able to improvise on the scorecard comprising of quality of raw materials, delivery timelines, cost of delivery and responsiveness to the demand. It was seen that $85 \%$ reported an improvement in the scorecard, whereas $15 \%$ did not see an improvement. This stems from the fact that the purchasing team was dealing with multiple suppliers, some of whom had adapted well to the supplier collaboration portal Ariba, while others were still catching up.

B. H2: Having a reliable WMS improves the inventory accuracy and warehouse productivity.

Various inventory reports were analyzed to ascertain the inventory accuracy in the first 5 weeks after going live. The warehouse operators and material planners were interviewed to obtain a direct feedback on the inventory accuracy.

\section{1) Cycle Count Accuracy}

Cycle count accuracy represents how closely the system stock matches to the physical stock. Higher accuracy means the WMS system stock location and the physical stock location are closely matched. It is seen that the number of bins counted increased from just above 20 in the first week to nearly 95 in the fifth week. And the corresponding count accuracy seen in week 1 was $95 \%$ while in week 5 it was $89 \%$.

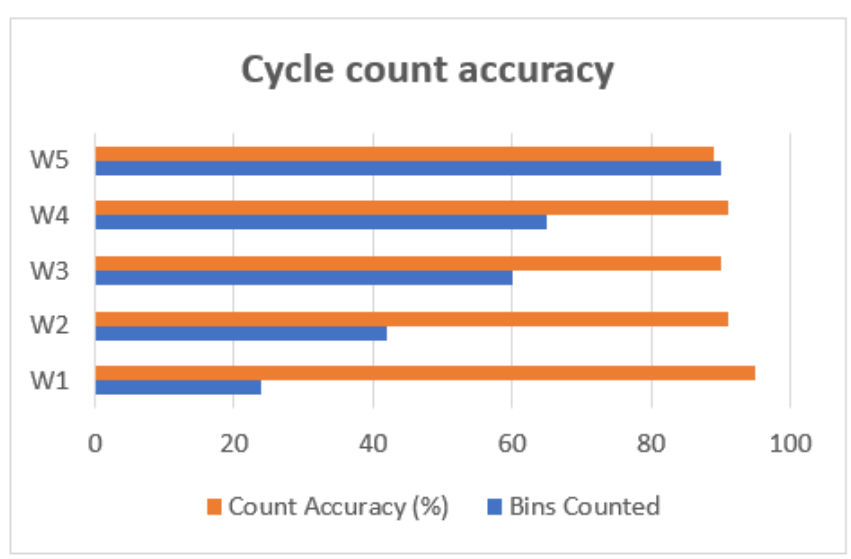

Fig. 6. Cycle count accuracy.

\section{2) Workload Planning}

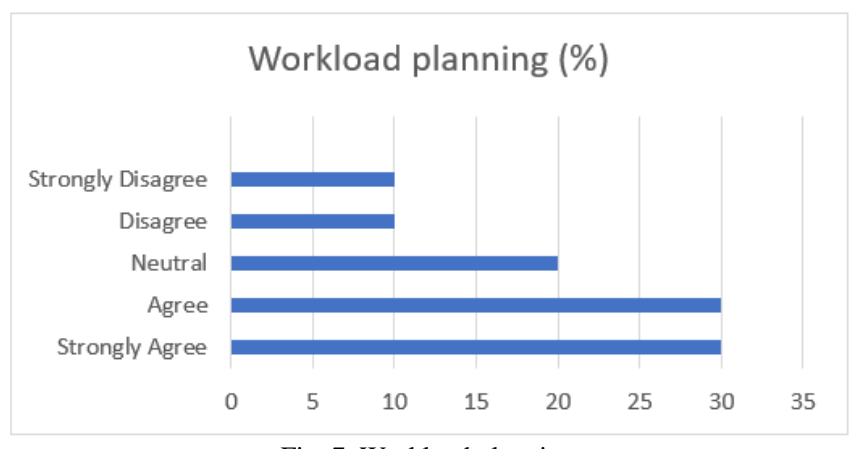

Fig. 7. Workload planning.

About 20 warehouse team leads responded when asked if the WMS system was helping them with the visibility of the net workload during the shift and if they were able to allocate and balance the workload across inward receipt, production staging and outbound picking. $30 \%$ of the respondents answered as strongly agree and agree. $20 \%$ were neutral and $10 \%$ responded as disagree and strongly disagree respectively.

\section{3) Picking Efficiency}

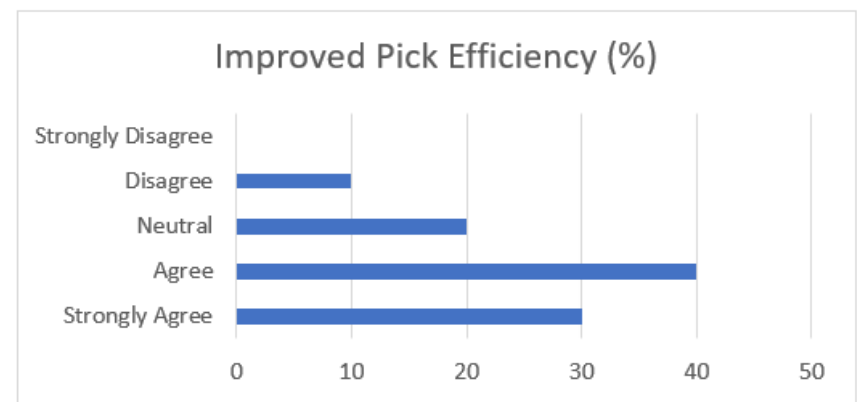

Fig. 8. Picking efficiency.

Around 30 warehouse operators responded when asked if the paperless picking through the RF gun was allowing them to execute picking faster and if that allowed them to complete more pick jobs in a shift. $30 \%$ of the respondents strongly agreed, $40 \%$ agreed, $20 \%$ were neutral and $10 \%$ disagreed in their feedback.

\section{4) Operator work Traceability}

20 warehouse team leads responded when asked if they were able to utilize the WMS reporting to trace the productive work done by each operator in the shift and if that helped them monitor the individual productivity. $80 \%$ of the team leads responded yes whereas $20 \%$ responded as No. 


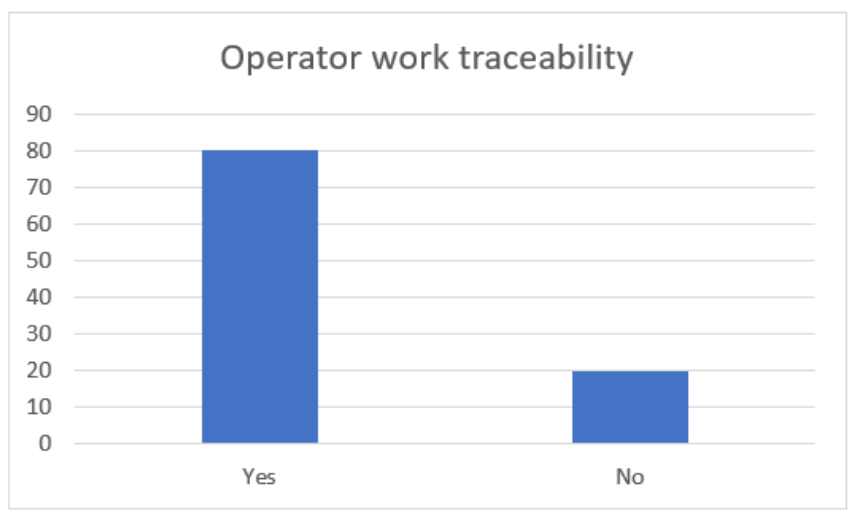

Fig. 9. Operator work traceability.

C. H3: When WMS and MES are connected seamlessly, they bring out the optimum productivity.

The WMS and MES integration provided the opportunity for the warehouse and production operators to communicate effectively using a common platform.

\section{1) Unwanted RM movements}

A survey question was responded by a group of 20 warehouse operators and 20 Production operators about the reduction in unwanted/non-required movements of materials between the warehouse and production due to unplanned schedule changes.

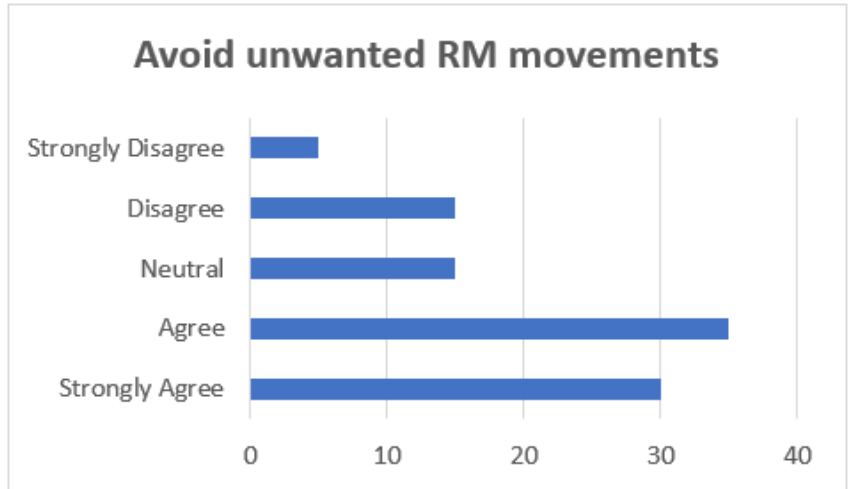

Fig. 10. Responses to the question on reduction in unwanted movement of raw materials due to production schedule changes.

$65 \%$ of the respondents agreed to have observed a reduction in the unwanted movement, around $15 \%$ were neutral while $20 \%$ responded as disagree or strongly disagree. The higher positive response was possible due to an option available on the operator dashboard to allow the production operators to stop the automatic ordering of raw materials.

\section{2) Reduced Downtime}

The group of 40 respondents were asked about their observation on the downtime before and after the implementation.

Nearly $50 \%$ strongly agreed to a reduced downtime post the project implementation, $25 \%$ agreed, $5 \%$ were neutral, $15 \%$ disagreed, and $5 \%$ strongly disagreed. It is seen that more than $75 \%$ agreed to a reduction in downtime.

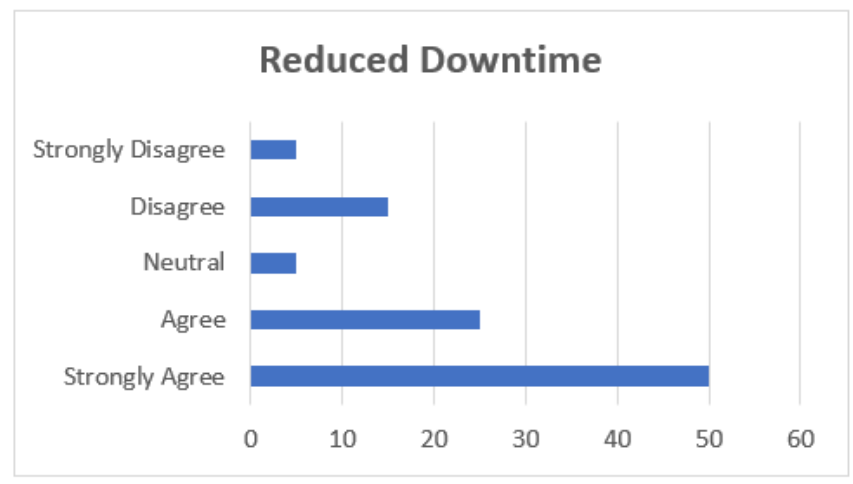

Fig. 11. Downtime.

\section{3) Quality Notifications}

40 respondents responded when asked regarding the impact of automatic quality notifications to record the timely quality checks.

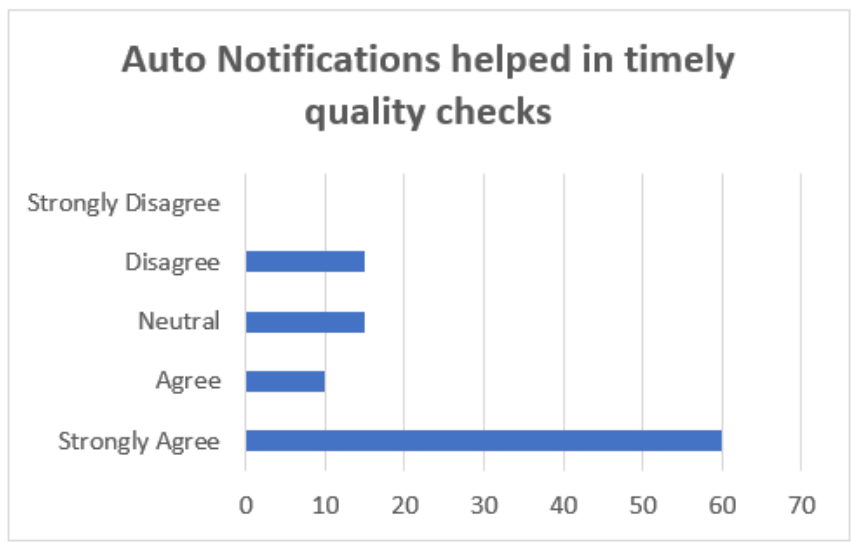

Fig. 12. Quality Notifications.

$60 \%$ of the respondents strongly agreed that the automatic quality notifications helped in timely quality checks, whereas $10 \%$ agreed, and $15 \%$ responded as neutral or disagree.

\section{4) Production Schedule Report}

About 20 warehouse team leads responded when asked about the helpfulness of the production schedule report in planning the warehouse activities in terms of the number of resources to be present in the shift, and the resource allocation to perform the key activities like inward receipts, production supply and stock takes.

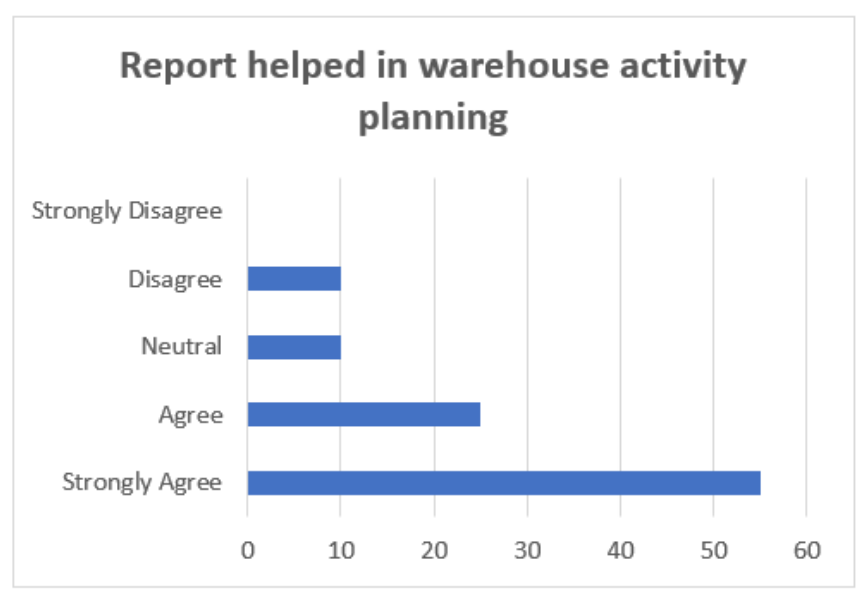

Fig. 13. Production Schedule report. 
$55 \%$ of the respondents strongly agreed to the helpfulness of the report, $25 \%$ agreed, while $10 \%$ were neutral or disagreed.

D. H4: New age WMS and MES solutions have a considerable advantage over the traditional legacy systems.

The senior leadership group of 10 respondents at the breweries was interviewed about the improvements in key metrics after 6 weeks of implementation. The questions were specific to the similar features available in the old legacy system.

Production costs (PC) - The visibility of real time costs associated to raw material and resources that went into each production run and its variance to the planned costs for that run.

Inventory accuracy (IA) - The stock accuracy in the WMS and its traceability within the warehouse.

Sales and Operations planning (SOP) - The ability to read the reports on production output and inventory to effectively plan the sales and operations.

Material Planning (MP)- The ability to plan long term purchasing contracts, just in time purchasing, effectively do the stock transfers, manage offsite material storage, and manage subcontracting.

Improved Productivity (IP) - If the sites were able to utilize the business intelligence reports on costs, inventory, sales, operations, etc. and take informed decisions to improve the overall productivity.

The responses to the above questions are given in the graph below.

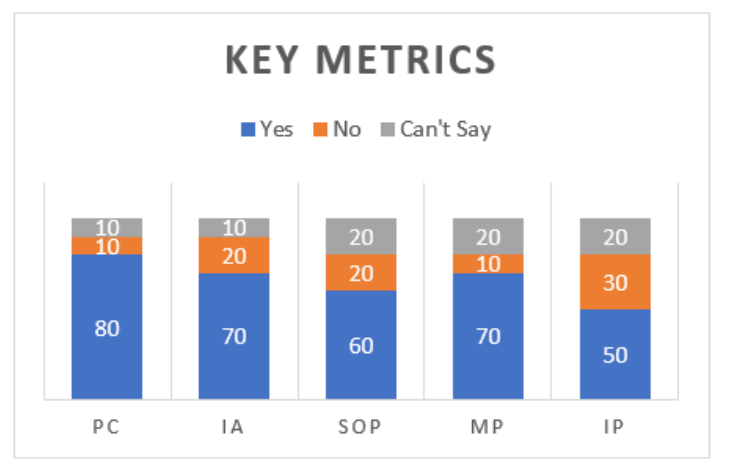

Fig. 14. Key Metrics responses.

\section{DISCUSSION}

This section outlines the overview of the hypothesis analysis. H1 examines the benefits of electronic integration with suppliers. The implementation followed a low volume start-up with a few inbound deliveries in the first two weeks which gradually increased in the following weeks. As the users were acclimating to the new ways of working, it was taking longer than expected to receive the inward goods. However, it was a quick learning curve and by week 3 the average receipt time was nearing the expected times. The ASN accuracy depends largely on the suppliers doing the job correctly. It was seen that in some instances physical delivery from the supplier arrived but there was no electronic ASN for that delivery, leading to supplier follow-ups and delays of inward reception. As the new suppliers began sending ASN, the ASN accuracy fluctuated between $80 \%$ and $90 \%$. The warehouse team leads, and team members were asked about the improvements in the goods receipt process, and they agreed that the new process was simplified and more accurate in comparison to the traditional process they had followed. The supplier scorecard results confirmed that most of the suppliers were able to meet the client's expectations and the client was able to take advantage of that and perform an effective material planning.

$\mathrm{H} 2$ analyses the improvement in inventory accuracy and warehouse productivity by measuring some key metrics in these areas and by comparing their performance in the legacy systems. The number of bins cycle counted gradually increased from week 1 until week 5 to ensure the increased material movements did not affect the inventory accuracy. The WMS had some important reports that allowed the team leads to have visibility of the planned inward goods and production schedule for the day and week, which allowed them to effectively plan the number of resources per shift and also to allocate the work to resources. The new ways of working involved paperless picking and the operators received the pick list on the RF devices, which was very effective in planning and optimizing the operator picking experience. The team leads also had the reports available to see the net work done by each operator. There were some users who needed more support to effectively perform their duties and were not very happy with the usability of new systems.

$\mathrm{H} 3$ describes the benefits of integration between the WMS and MES. Unplanned changes in production schedule and unplanned breakdowns pose a high risk of delivering unwanted raw materials to production. This results in additional work for the warehouse operators to move the pallets back from production to the warehouse. All these unwanted movements lead up to significant resource costs and impacted the other planned warehouse activities. With the feature available in the MES operator dashboard, the production operators could proactively inform the warehouse to stop the material delivery in the event of such unforeseen incidents. It was also observed that there was a significant reduction in the production downtime. The automatic notifications to do quality checks was a highly liked feature in the operator community and it helped them to a greater extent in performing the timely quality checks, ensuring the organizational quality standards. The production report aided the warehouse team leads in organizing the workload of the operators. A small group of people was finding it difficult to fully exploit the advantages of the new features.

$\mathrm{H} 4$ focused on the management information systems and tools. Various reports were at their disposal in comparison to the old legacy system including cost benefit analysis, sales performance, operational performance metrics, among others. It attempted to gauge the usefulness of these metrics in decision making, planning, and forecasting. It was observed that senior management found the business performance metrics information to be exceedingly helpful.

\section{CONCLUSION}

After carefully studying the positive impact of the key solution elements and completing the data analysis, the research hypotheses are examined in this section. Hypothesis 1 talks about the better collaboration when suppliers are connected electronically. Hypothesis 2 stresses on the 
improved supply chain performance within the organization due to a reliable WMS system in place. Hypotheses 3 refers to productivity improvement due to well-integrated WMS and MES systems. Hypothesis 4 relates to the advantages of WMS and MES over the legacy systems. Based on the analysis of key business metrics after the project implementation and the inference from survey results, it can be concluded that WMS and MES project implementation with diligent business analysis and effective user training brings about a huge positive change in business performance.

\section{REFERENCES}

[1] Atieh, A. M., Kaylani, H., Al-abdallat, Y., Qaderi, A., Ghoul, L., Jaradat, L., \& Hdairis, I. (2016). Performance Improvement of Inventory Management System Processes by an Automated Warehouse Management System. Procedia CIRP, 41, 568-572. https://doi.org/https://doi.org/10.1016/j.procir.2015.12.122.

[2] Block, C., Lins, D., \& Kuhlenkötter, B. (2018). Approach for a simulation-based and event-driven production planning and control in decentralized manufacturing execution systems. Procedia CIRP, 72, 1351-1356.

[3] Harfmann, B. (2017). Powering up with software solutions: WMS, WCS optimize warehouse operations. Beverage Industry, 108(11), 72 73.

[4] Hoffman, M. (2013). 6 Ways WMS Can Improve Operations. Food Logistics, 143, 46-49.

[5] Jaskó, S., Skrop, A., Holczinger, T., Chován, T., \& Abonyi, J. (2020). Development of manufacturing execution systems in accordance with Industry 4.0 requirements: A review of standard- and ontology-based methodologies and tools. Computers in Industry, 123, 103300.

[6] Kim, T. H., Jeong, J., \& Kim, Y. (2019). A Conceptual Model of Smart Manufacturing Execution System for Rolling Stock Manufacturer. Procedia Computer Science, 151, 600-606.

[7] Klie, L. (2005). Warehouse Hangover Helper. Food Logistics, 79, 28 31.

[8] Lee, C. K. M., Lv, Y., Ng, K. K. H., Ho, W., \& Choy, K. L. (2018). Design and application of Internet of things-based warehouse management system for smart logistics. International Journal of Production Research, 56(8), 2753-2768.

[9] Menezes, S., Creado, S., \& Zhong, R. Y. (2018). Smart Manufacturing Execution Systems for Small and Medium-sized Enterprises. Procedia CIRP, 72, 1009-1014.

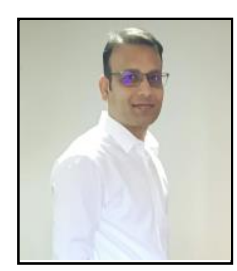

Sushant Siddharth Wanjari is a qualified Mechanical Engineer with post graduate diploma in Management Studies from Tier-I educational institues in India.

He has a rich professional experience in Logistics,

Warehousing and Transportation domains of Supply Chain. He has worked for several multinational clients and helped them achieve business transformation goals led by IT. At the time of writing this research paper, he was working as Principal Consultant - Supply chain with DXC Oxygen, Australia.

Mr. Wanjari takes keen interest in the latest innovation in Warehousing and Transportation and he is active members of several supply chain associations. 